\title{
Las pinturas románicas de San Martín de Elines
} (Santander)

Antonio DE ÁVILA JUÁREZ

Recibido: 5-5-2013 / Aceptado: 27-6-2013

RESUMEN: Los fragmentos de pintura románica conservados en la colegiata de San Martín de Elines (Santander) habitualmente han sido relacionados con los de Santa María de Taüll y Maderuelo. Su reciente restauración nos ha brindado la oportunidad de llevar a cabo un estudio más profundo de sus frescos; estudio hasta ahora sólo abordado tangencialmente por la historiografía especializada. En nuestro trabajo incorporamos algunos de los resultados obtenidos durante su restauración. Estos resultados parecen afianzar sus conexiones técnicas con los frescos de los condados catalanes, pero no excluyen, en nuestra opinión, sus lazos artísticos con San Baudelio, Maderuelo y Gormaz.

Palabras clave: pintura románica, restauración, Santa María de Taüll, Maderuelo, San Baudelio de Berlanga, San Miguel de Gormaz.

ABSTRACT: The Romanesque painting fragments preserved in the collegiate church of San Martín de Elines (Santander) have been commonly associated with those of Santa María de Taüll and Maderuelo. Its recent restoration has given us the opportunity to carry out a deeper study of its frescoes; study so far tangentially approached by specialized historiography. In our work we incorporate some of the results obtained during its restoration. These results seem to strengthen their technique connections with the frescoes of Catalan counties, but do not exclude, in our opinion, their artistic ties with San Baudelio, Maderuelo and Gormaz.

Key words: Romanesque painting, restoration, Santa María de Taüll, Maderuelo, San Baudelio de Berlanga, San Miguel de Gormaz.

La colegiata de San Martín de Elines, situada en el santanderino valle de Valderredible ${ }^{1}$, a sólo quince kilómetros de

${ }^{1}$ El edificio fue construido sobre las ruinas de un monasterio del siglo X. Se cree que el levantamiento del nuevo monasterio, más tarde colegiata, se llevó a cabo inmediatamente después de su hundimiento en 1102 (ruit ecclesia Santi Martini de Helines). En este mismo siglo, al que corresponden las pinturas, San Martín era ya una importante fundación benedictina. Su declaración como Monumento Histórico-Artístico se produjo el 3 de junio de 1931.
Tubilla del Agua², es una de las joyas de la arquitectura románica cántabra ${ }^{3}$. El edifi-

${ }^{2}$ La comarca de Valderredible, como casi toda la actual provincia de Santander, perteneció en su día al antiguo reino de Castilla. Los frescos de Tubilla del Agua (Burgos), localidad muy próxima a San Martín de Elines, fueron probablemente ejecutados por el mismo taller.

${ }^{3}$ No obstante, las características de su románico son, como señala Eálo de Sá, “ajenas al estilo peculiar de la provincia de Santander". En efecto, para esta autora, sus rasgos fundamentales provendrían de la Meseta 
cio también debió albergar en su interior una importante colección de pinturas. Lamentablemente, el escaso prestigio social del que ha gozado el arte pictórico de este período estuvo a punto de originar su total destrucción ${ }^{4}$. Con todo, es posible que la reducida presencia de los fragmentos conservados llegue a adquirir, gracias a su reciente restauración y al descubrimiento de un extenso conjunto mural en San Miguel de Gormaz y de nuevos fragmentos en San Martín de Ávila (obras quizás de las mismas manos que policromaron San Baudelio de Berlanga y Maderuelo) $)^{5}$, una nueva y mayor relevancia, a la que esperamos contribuir, modestamente, con este trabajo de investigación.

(Cf.: M. EÁLO DE SÁ, El románico de Cantabria en sus cinco colegiatas, Ed. Centro de Información y Publicaciones de la Comunidad Autónoma de Cantabria, Santander, 1978, p. 87).

${ }^{4}$ San Martín de Elines no es una excepción en el "martirologio" de las pinturas románicas. Al parecer el templo había permanecido blanqueado hasta el año 1925. Durante el lustro siguiente se procedió a su desencalado, salvo en la zona del ábside, protegida por un retablo del siglo XVIII. En plena Guerra Civil, el retablo sería quemado y el recinto utilizado como alojamiento militar. Concluida la contienda, algunos vecinos quisieron completar el desencalado de la colegiata. Al hacerlo no tardaron en aparecer los frescos, pero fueron destruidos por ser considerados de escaso valor. Afortunadamente, el despropósito logró ser detenido in extremis, aunque sólo a tiempo de salvar los contados restos que hoy permanecen in situ, y que han sido restaurados en 2011. La memoria de la intervención llevada a cabo en las pinturas aporta varios datos de interés; datos que iremos comentando a lo largo del artículo (Cf.: R. TERA SAAVEDRA, Intervención de las pinturas románicas de San Martín de Elines, Cantabria. Propuesta metodológica para el estudio de su contexto histórico-artístico basado en el análisis de materiales. Recuperado de http://hdl.handle. net/10902/1609.

${ }^{5}$ A este grupo de templos y a sus pinturas lo denominaremos grupo extremaduriense, ya que se halla localizado en las llamadas Extremaduras castellanas.

\section{ARQUITECTURA}

En el exterior del templo, obra de transición de los siglos XI al XII ${ }^{6}$, destacan su voluminosa linterna, el variado repertorio de sus canecillos, una llamativa torre cilíndrica adosada al costado sur, $\mathrm{y}$, sobre todo, su cabecera semicircular, indudablemente lo más sobresaliente del conjunto (Fig. 1). Dos columnas exentas, apoyadas en sendos plintos o pequeños contrafuertes, dividen verticalmente su fachada hasta llegar a la cornisa. En cada una de las tres calles se abre una aspillera de medio punto. Diversos complementos arquitectónicos perfectamente labrados (columnillas, capiteles, impostas, etc.) y grandes arcos ciegos enmarcan estas ventanas, proporcionándole al ábside de San Martín su reconocido atractivo artístico ${ }^{7}$.

El acceso al interior se realizaba a través de dos puertas: una románica, en el paramento meridional de la nave, hoy tapiada, y la actual de entrada, situada en el hastial y de idéntico estilo. La nave, bajo artesonado, es el tramo más sencillo. Mayor interés presenta el falso crucero de la linterna, delimitado por cuatro grandes columnas cilíndricas coronadas en capiteles bellamente historiados ${ }^{8}$. Sobre ellos descargan cuatro arcos torales, sostenes de la bóveda de media esfera que cubre este espacio. En el muro septentrional existe una tercera puerta9: la

${ }^{6}$ A los pies del templo se levanta un pequeño claustro de un solo piso. Este claustro, aunque renacentista en casi su totalidad, conserva interesantes restos del aún llamado por algunos arte mozárabe, o, por otros, de repoblación.

${ }^{7}$ Las tres ventanas no son, sin embargo, exactamente iguales, ya que entre ellas presentan algunas diferencias, siendo la izquierda la más sencilla de todas.

${ }^{8}$ Jesús Herrero Marcos ha interpretado el sentido global de la decoración escultórica de Elines como expresión de la victoria del Bien contra el Mal (Cf.: J. HERRERO MARCOS, Arquitectura y simbolismo del románico en Cantabria, Ars Magna Ediciones, Madrid, 1996, pp. 120-201).

9 Eálo de Sá considera que esta puerta pudo ser también exterior hasta la segunda mitad del siglo XII (Cf.: M. EÁLO DE SÁ, Op. cit., p. 43). 
de la sacristía, pequeña estancia de bóveda apuntada y paredes extraordinariamente gruesas $^{10}$.

Los muros del presbiterio se articulan mediante dos arcos ciegos de medio punto soportados por columnas con capiteles intensamente esculpidos. Por arriba una imposta de billetes marca el inicio del siguiente nivel, donde se abre, en perfecta alineación con la columna medianera de los arcos inferiores, una solitaria saetera ${ }^{11}$. Otra imposta con palmetas de ocho puntas señala el final de este piso alto y el arranque de la bóveda de cañón. Bajo la concha absidal prosiguen las impostas del presbiterio. Su medio tambor se halla estructurado igualmente mediante arquerías: cuatro ciegas, abajo, y cinco arriba, tres con aspilleras abocinadas.

\section{PINTURAS}

\section{Técnica}

$\mathrm{Su}$ reciente restauración nos ha permitido conocer con mayor detalle sus aspectos técnicos. Así sabemos que fueron ejecutadas al fresco con retoques a seco (probablemente de temple al huevo) sobre un mortero de dos capas. La última, el enlucido, desprovista de áridos, fue aplicada antes de que hubiese fraguado la primera, el enfoscado. El dibujo a sinopia se realizó sobre este

\footnotetext{
${ }^{10}$ Según Eálo de Sá tal vez pudo ser pensada para levantar una torre cuadrada al gusto castellano, aunque finalmente se dedicó a sacristía (Cf.: M. EÁLO DE SÁ, Ibidem).

11 Con posterioridad, la escasa luz de estos vanos serviría de disculpa para ampliar la correspondiente al mediodía. Según Bertín Gutiérrez López, por uno de los párrocos, hace unos cien años (Cf.: B. GUTIÉRREZ LÓPEZ, Colegiata de San Martín de Elines, Editur, Burgos, 2000, p. 71). Sin embargo, C. García García y M. A. García Guinea sitúan el "arreglo destructor" en los siglos XVII-XVIII (Cf.: C. GARCÍA GARCÍA y M. A. GARCÍA GUINEA, "San Martín de Elines", Enciclopedia del Románico en Cantabria, Fundación Santa María la Real / Centro de Estudios del Románico, Aguilar de Campoo (Palencia), 2007, t. III, pp. 1426-1474).
}

arricio para que pudiera traslucirse bajo el intonaco. Como pigmentos se emplearon calcita, negro carbón vegetal, tierra roja, tierra amarilla, tierra ocre y aerinita, que es la que proporciona el color azul, un color, como veremos, fundamental para el estudio de estos frescos.

\section{Iconografía}

Resulta razonable suponer, por los fragmentos conservados, que toda la cabecera estuviera decorada en su día con frescos románicos. Los más conocidos se hallan situados junto a una de las ventanas absidales, concretamente la del lado de la Epístola, próximos, por lo tanto, al muro del presbiterio. Se trata de dos personajes masculinos, seguramente apóstoles ${ }^{12}$, separados en altura por la propia imposta del ventanal (Fig. 2). El superior, que es el que se halla en mejores condiciones, se representa sentado, imberbe, con nimbo, y enmarcado por un arco de medio punto (Fig. 3). De este arco se conserva un único capitel, el derecho del espectador. Su interés radica en que sigue de cerca los patrones berlangueses y en que forma parte de la decoración mural de Santa María de Taüll ${ }^{13}$. De hecho, Yarza atribuyó a estos dos conjuntos una data anterior a la de Maderuelo basándose precisamente en el supuesto origen catalán de este capitel y en su desaparición de las pinturas segovianas. Consta de un astrágalo redondeado, tal vez tórico (en Taüll recto o cilíndrico), y de un tambor semiesférico ornamentado con decoración vegetal. La misma decoración, o muy similar, se repite en los capiteles de San Baudelio y San Miguel de Gormaz.

\footnotetext{
$12 \mathrm{Su}$ emplazamiento absidal hace probable la presencia de una Maiestas Domini o de otra importante teofanía.

13 Transposiciones pictóricas, según Joaquín Yarza, de los esculpidos en edificios del Imperio Germánico durante el siglo XI, e igualmente, pero más tarde, en la Lombardía (Cf.: J. YARZA, “Un cycle de fresques romanes dans la paroisse de Santa María de Taüll", Les Cahiers de Saint-Michel de Cuixá, n.․XXX, 1999, pp. 121-
} 199). 
También llama la atención, por ser infrecuente en el contexto castellano, el azul de una de las fajas del fondo. Su tonalidad contrasta con la cálida presencia de los colores tierras. Sobre esta base fajeada se recorta la aureola circular del apóstol. En su mano derecha, que aparece envuelta por el manto, sostiene un libro, del que se destaca su importancia con un gesto indicativo de la otra mano. La tipología de esta imagen es similar a la de las figuras apostólicas de Maderuelo, con las que mantiene indiscutibles lazos formales, aun presentando también ciertas peculiaridades, como la abertura del manto, que deja ver la torpe resolución de algunas zonas corporales (cintura y pierna), y donde se echa en falta la precisa, a la par que elegante, geometría madoliense ${ }^{14}$.

El estado del segundo apóstol, el más próximo al suelo, es muy deficiente (Figs. 4 y 5). Posiblemente se representó de cuerpo entero, aunque en la actualidad conserva sólo la mitad superior. En su mano derecha sostiene también un ejemplar del Evangelio, pero esta vez en alto, en señal de enaltecimiento. Por contra, de su fondo ha desaparecido todo atrezo arquitectónico, aunque se halla igualmente recorrido por bandas cromáticas, en las que vuelve a destacar el azul antes comentado.

El deterioro de las dos figuras, ahora atemperado por su reciente restauración, no impide detectar cierta desmaña compositiva $^{15}$. Como, por ejemplo, la mutilación

\footnotetext{
14 En realidad, tanto en Maderuelo como en el resto de las pinturas pertenecientes a este hipotético grupo, es imposible contemplar estas partes del cuerpo, pues se hallan siempre cubiertas por los mantos. Esta figura es, en ese sentido, excepcional.

15 Aunque se haya de reconocer que no es fácil encajar las figuras en una superficie tan estructurada como el ábside, es evidente que las pinturas de San Martín no parecen preocuparse demasiado por el marco arquitectónico cuando éste supone un obstáculo. Esta parece ser una de las características de las obras pertenecientes al grupo estremaduriense. Véase el corte radical dado al nimbo de San Miguel en la psicostasis de Gormaz, el aplastamiento de los Magos que visitan al rey Herodes en esta misma iglesia soriana, o el brutal corte del Agnus Dei en Tubilla del Agua.
}

originada por la imposta sobre el cuerpo del primer apóstol, o el corte sumamente brusco que esa misma pieza provoca en el nimbo del segundo (por debajo existía superficie suficiente para haber articulado otra solución).

Los restos pictóricos del piso bajo del hemiciclo decoran las dos hornacinas centrales. En su momento estos arcos estuvieron ribeteados con grisallas de roleos vegetales, de las que, lamentablemente, sólo se mantienen in situ unos pocos fragmentos ${ }^{16}$.

En el primer tímpano (arco izquierdo), se observan dos aves bebiendo de un recipiente con forma de copa sobre el que desciende la paloma del Espíritu Santo (Figs. 6 y 7$)^{17}$. El color del fondo es de un incierto cromatismo pardo-rojizo, no demasiado alejado por otra parte del empleado en las pinturas bajas de Berlanga ${ }^{18}$. Este fondo es casi con toda seguridad un repinte, pues debajo se ha descubierto una franja horizontal de color azul. Las dos aves lucen largos cuellos y garras en sus patas, y entre sus colores, que son idénticos pero alternados, vuelve a aparecer el azul. Seguramente estemos ante sendas águilas, pues tanto el hálito blasonante de su estricta simetría como sus propios rasgos armonizan perfectamente con la nobleza de estas rapaces y con el homenaje que parecen rendirle al motivo central. Éste, por su parte, puede ser interpretado de diferentes maneras, ya que

\footnotetext{
16 Esta clase de grisallas aparecen también en San Baudelio. Milagros Guardia Pons afirma que con ellas se pretendía traducir pictóricamente relieves escultóricos de inspiración romana (Cf.: M. GUARDIA PONS, San Baudelio de Berlanga, una encrucijada, Universidad de Barcelona et al., Barcelona, 2011, pp. 242 y ss.).

17 De este posible cáliz ha sobrevivido parte de su mitad derecha y algunos restos de la otra mitad; fragmentos que han permitido reconstruirlo con bastante fidelidad. Debemos señalar también que la paloma del Espíritu Santo, a diferencia de las representadas en las ventanas absidales del grupo extremaduriense, aparece aquí con sus extremidades inferiores totalmente despegadas del cuerpo.
}

${ }^{18}$ Cf. R. TERA SAAVEDRA, Op. cit., p. 28. 
es factible verlo como un cáliz, como una pila bautismal, e, incluso, como la fuente de la gracia. De esta última manera lo entiende, por ejemplo, Joan Sureda en Santa María de Taüll ${ }^{19}$, donde dos pavones beben de un objeto similar; situación parecida se repite en la viga de $\mathrm{Cardet}^{20}$. Rosa Tera Saavedra cita varios ejemplos más de esta tipología ${ }^{21}$, entre ellos el capitel del muro sur del presbiterio de San Andrés de Padilla de Arriba (Burgos) y el capitel del arco triunfal de la iglesia de la Natividad de Nuestra Señora de Valdearnedo (Burgos). En Elines, la presencia de las águilas podría servir para apoyar, dadas las connotaciones bautismales de estas aves, un simbolismo relacionado con el sacramento de la iniciación. No obstante, su emplazamiento en la parte central del ábside parece sugerir una significación eucarística.

Los fragmentos pertenecientes al arco derecho se conservan bastante más dañados (Figs. 8 y 9). El fondo, con el mismo cromatismo, estaba dominado por una maraña de trazos inconexos. Estos trazos han dificultado durante mucho tiempo la correcta lectura de los motivos iconográficos. Sin embargo, en su mitad derecha se distinguía un ave pintada según los patrones del taller extremaduriense (Fig. 10). De hecho, esta ave sólo había perdido una parte significativa de su anatomía: el pico, que debió de ser de reducido tamaño. Debajo de ella se intuían muy vagamente dos más pequeñas (Fig. 11) - ¿sus polluelos? - , y, en la mitad contraria, y asimismo con mucha dificultad, otra como la primera. Por último podían también notarse, en la zona medial y superior del semicírculo, algunas formas de difícil reconocimiento (Fig. 12). Éstas estaban sujetas, mediante finas líneas curvas de color blanco, a unas líneas horizontales bastante más gruesas, cruzadas a su vez perpendi-

19 Cf.: J. SUREDA PONS, La pintura románica en Cataluña, Alianza Editorial, Madrid, 1981, p. 289.

${ }^{20}$ Cf.: J. SUREDA PONS, Op. cit., p. 196. Esta viga policromada pertenece a las colecciones del Museo Nacional de Arte de Cataluña.

${ }^{21}$ Cf.: R. TERA SAAVEDRA, Op. cit., pp. 18-19. cularmente con otras verticales. El conjunto parecía definir una especie de percha.

Sin duda, de los dos arcos éste era el que planteaba y continúa planteando más dificultades, ya que, a pesar de los esfuerzos realizados por el equipo restaurador, sigue siendo difícil esclarecer su iconografía $^{22}$. No obstante, podríamos resumirla como una pareja de aves acompañada de sus crías, y, en medio de ellas, una percha de la que pende atado por sus extremidades un animal, posiblemente una nueva ave. Rosa Tera Saavedra interpreta estas figuras como cuatro gallos portando un animal desconocido ${ }^{23}$. Por nuestra parte, pensamos que su fuente puede hallarse en los Bestiarios, en alguna de las historias sobre la caza de la perdiz ${ }^{24}$, concretamente en la inspirada en el famoso tratado de los animales del escritor griego-romano Claudio Eliano ${ }^{25}$. En ella se describe la utilización de la perdiz doméstica como reclamo cinegético, para lo cual el cazador la sitúa junto a una trampa previamente preparada. Desde allí provoca con su canto al macho silvestre. Entonces, cuando éste responde y se adelanta para defender a su pollada ${ }^{26}$, finge tener miedo y retrocede, atrayéndolo así hacia la trampa o lazo donde queda atrapado. Es evidente que no podemos saber con seguridad si nos hallamos ante la representación de esta fábula; pero la mayoría de sus elementos

22 El equipo restaurador ha llevado a cabo un encomiable trabajo de interpretación, especialmente en el caso de este fondo, particularmente confuso, donde podrían haberse producido interpretaciones erróneas por la formación de pareidolias. Con anterioridad se habían visto las imágenes de un cordero, una esfinge y una arpía.

${ }^{23}$ Cf.: R. TERA SAAVEDRA, Op. cit., pp. 19 y ss.

${ }^{24}$ Cf.: S. SEBASTIAN, El Fisiólogo atribuido a San Epifanio seguido de el Bestiario Toscano, Ediciones Tuero, Madrid, 1987, p. 61.

25 Cf.: C. ELIANO, De natura animalium, IV, 16 (Versión castellana: Historia de los animales, Ed. Gredos, Madrid, 1984).

${ }^{26}$ Se pensaba que las perdices robaban los huevos de los otros nidos. 
parecen refrendarlo, desde el propio reparto, integrado por dos aves adultas y dos pequeñas, a las patas atadas a una percha, que sería la trampa. Aun siendo la opinión de los bestiarios sobre estas volátiles francamente negativa, esta leyenda sería aprovechada con fines edificantes ${ }^{27}$, mostrando la insensatez de los hombres que, atraídos por el pecado (el canto de la perdiz), caen en las trampas y lazos del cazador (el diablo).

Tras este breve recorrido por las pinturas, no sería prudente deducir, con tan escasos elementos, la clave general del programa iconográfico, cuya temática (un apostolado y un posible motivo eucarístico) nada tiene de extraña en un ámbito absidal. Por otra parte, el mensaje moralizante de las supuestas perdices tampoco tendría por qué desentonar de ese mismo contexto, si bien no parece mantener ilación con el significado sacramental del primer arco.

Una vez descritos y analizados los motivos iconográficos, es necesario estudiar también su relación con los frescos de las Extremaduras castellanas, con los que cabe la posibilidad de que estén emparentados. En lo que respecta a los aspectos formales, suelen destacarse, por simpatía iconográfica, sus conexiones con Maderuelo. No podemos, empero, dejar de recordar las particularidades anteriormente indicadas, tales como el color azulado presente en algunas zonas, el oscuro fondo burdeos de los arcos del hemiciclo (repinte del que no sabemos si es contemporáneo de las pinturas), y la tosca resolución de ciertas partes de las figuras. Por otro lado, por su relajación frente al marco arquitectónico, se alejarían de la orquestada disposición madoliense, pero no así de los modi operandi de Gormaz, San Baudelio y Tubilla del Agua.

27 Según García Guinea este ave, la perdiz, aparece representada en uno de los canecillos del muro sur del presbiterio (Cf.: M. A. GARCÍA GUINEA, El románico en Santander, Ediciones de Librería Estudio, Santander, 1979, t. II, p. 532).
En cuanto al contexto histórico donde se enmarcaría la producción artística del grupo extremaduriense, parece haber acuerdo sobre la posibilidad de que personalidades relacionadas con el monarca aragonés Alfonso I el Batallador (a la vez señor de Castilla por su matrimonio con la reina Urraca, hija de Alfonso VI) hayan podido ser las promotoras de alguno de sus trabajos ${ }^{28}$. Quizás esta teoría puediera servir para aventurar la intervención de los maestros meseteños en la decoración de San Martín. Sin embargo, carecemos de documentación para abordar esta cuestión con garantías de historicidad. Con todo, sabemos que la colegiata fue un importante monasterio benedictino en el siglo XII; que la influencia del Batallador sobre estos territorios continuó tras su ruptura matrimonial; que la zona oriental de la provincia era en general proclive a lo aragonés; y, por último, que los dominios eclesiásticos castellanos sintieron un especial interés por estos territorios, ávidos de poseer vasallos y propiedades en Cantabria ${ }^{29}$. En todo caso, la situación específica de Valderredible permanece todavía confusa, pues los González de Lara - y muy especialmente el Conde Rodrigo, cuñado de la reina y opuesto al rey-dominarían tras la ruptura real varias mandaciones montañesas y foramontanas próximas o colindantes con Elines ${ }^{30}$.

\footnotetext{
${ }^{28}$ Isidro Bango Torviso discrepa, sin embargo, de esta clase de explicaciones, defendidas especialmente por Milagros Guardia, a las que califica de "paraguas sociopolítico", pues piensa que los vínculos entre todos estos templos (incluidos los de los condados pirenaicos) se deben a las facilidades proporcionadas por una nueva realidad eclesiástica (Cf.: I. BANGO TORVISO, "El protagonismo de Soria en el origen de la pintura románica castellanoleonesa: las pinturas de San Miguel de Gormaz. Un programa iconográfico de carácter funerario", en AA. VV., Jornadas de estudio y difusión del patrimonio, Diputación Provincial de Soria, Soria, 2010, pp. 89-118).

${ }^{29}$ Cf.: C. DIEZ HERRERA, “Los señoríos eclesiásticos en la Cantabria medieval", en R. RAMOS MARURI (coord.), La Iglesia en Cantabria, Obispado de Santander, Santander, 2000, pp. 137-157.

${ }^{30}$ Cf.: M. A. GARCÍA GUINEA, Op. cit., 1979, t. I, pp. 148 y ss.
} 


\section{Conclusiones}

En primer lugar, debemos decir que aunque valoramos las indudables cualidades artísticas de la que hacen gala los frescos elinesenses, pensamos por las razones antedichas que su calidad es inferior a la de Maderuelo. Los trabajos efectuados sobre las pinturas indican, además, que las dos figuras apostólicas fueron técnicamente ejecutadas de modo diferente. Estas diferencias - en absoluto despreciables - llevan a Rosa Tera Saavedra a plantearse la posibilidad de que hayan sido realizadas por dos pintores distintos, cada uno con su propia técnica (la de la figura superior más tosca, la de la inferior de mayor calidad); posibilidad que a la propia autora le resulta, con razón, difícil de aceptar, aun viniendo sugerida por la propia $\operatorname{arqueología}^{31}$.

Sin embargo, no hay porque descartar la intervención de diferentes maestros. Su prestigioso status como cenobio benedictino durante el siglo XII (de la que es buena muestra su rica arquitectura, tan alejada de las carencias materiales y estructurales del grupo extremaduriense) no basta para excluir la intervención de artistas secundarios o de aprendices. De hecho, en el espléndido contexto de la colegiata santanderina, resulta muy llamativa la insólita austeridad, escultórica y ornamental, de algunas zonas. Para explicarla, García Guinea propuso la existencia de problemas financieros ${ }^{32}$; problemas que si realmente hubieran llegado a

${ }^{31}$ Cf.: R. TERA SAAVEDRA, Op. cit., pp. 27 y ss.

32 En efecto, García Guinea considera que la simpleza decorativa de algunas partes de la iglesia, como la puerta del hastial, contrasta radicalmente con la riqueza ornamental del resto del edificio (tanto que Eálo de Sá llegó a pensar que esta puerta no era original). Por ese motivo el autor sospecha que la construcción del templo pudo haber atravesado por dificultades económicas, y que estas dificultades pudieron originar a su vez la contratación de canteros de segunda categoría. No obstante, el mismo García Guinea reconoce que el románico santanderino no destaca por la existencia de portadas monumentales, y que algunas de ellas son "de vulgaridad desesperante" (Cf.: M. A. GARCÍA GUINEA, Op. cit., 1979, t. II, p. 540). producirse podían haber repercutido en las policromías. En este sentido cabe contemplar la posibilidad de que, por este hipotético motivo, o quién sabe si por premura, al tener que hacer frente a varios encargos (Tubilla del Agua), el taller se hubiera diversificado, permitiendo la intervención de maestros con distintos grados de formación y maneras de trabajar. En esta misma línea, puesto que las juzgamos cualitativamente inferiores a sus presuntas compañeras de la Meseta, podemos barajar otras opciones, en especial una no muy tenida en cuenta habitualmente $\mathrm{y}$ que consiste en valorar la capacidad de progresar, técnica, artística y profesionalmente, de todo pintor y también del románico, aun reconociendo que éste debía hacerlo dentro de unos márgenes particularmente estrechos. Esto, que parece una obviedad, no lo es tanto en su caso, pues los pintores de este período parecen nacer y morir para la Historia con unas destrezas y conocimientos ya fijados ${ }^{33}$. En nuestra opinión, la amplitud del inventario al que podrían pertenecer estas pinturas ${ }^{34}$, además de su considerable grado de coherencia, estilística e iconográfica, deberían de servir para abordarlas bajo una perspectiva más abierta. Por eso pensamos que si existe una mínima posibilidad de que las pinturas de Elines pertenezcan a la colección extremaduriense (y creemos que, en efecto, alguna hay), entonces ellas y las de Tubilla del Agua deberían ser catalogadas entre las primerizas del grupo. Veamos por qué.

Joaquín Yarza, Carmen García y Miguel Ángel García Guinea consideran, basándose entre otras cosas en la "similitud

\footnotetext{
${ }^{33}$ Un enfoque que es, en la mayoría de las ocasiones, por las peculiares características de la pintura románica, no sólo razonable, sino obligado. Por eso los estudiosos solemos explicar las diferencias entre conjuntos muy parecidos con expresiones calculadamente ambiguas: obras de un mismo círculo, productos de un mismo sustrato pictórico, pintor formado al lado de... etc.

34 San Baudelio, la Vera Cruz de Maderuelo, San Miguel de Gormaz, San Martín de Elines, San Miguel de Tubilla del Agua, San Martín de Ávila, Colección Leva, y, por último, una figura apostólica, en paradero desconocido, perteneciente a una iglesia conquense.
} 
de los capiteles", que los frescos de Elines se hallan más relacionados, estilística y cronológicamente, con los de San María de Taüll que con los castellanos. No obstante, creemos que no hay que concederle a dicho capitel tanto peso como el que le dan estos autores. Así, si analizamos, por ejemplo, los frescos de San Baudelio, encontramos un modelo de capitel similar al de Taüll (capitel derecho, escena del Ciego de Nacimiento), otro del estilo de Maderuelo (capitel izquierdo, escena del Ciego de Nacimiento, y figura de San Nicolás, en el testero), y, a mayores, otros dos sin duda parecidos y a la vez diferentes (Visitatio Sepulchri y Bodas de Caná). Es obvio que todos formaban parte del repertorio del taller, y que podían ser reutilizados en cualquier momento. Por otro lado, debido a lo poco conservado en Elines, no estamos en condiciones de saber si algunas de estas variantes llegaron a desempeñar algún papel en su decoración. Las pinturas recientemente descubiertas en San Miguel de Gormaz, en las que vuelve a aparecer este tipo de capitel, ilustran perfectamente cuán aleatoria podía ser su utilización. Pues de haberse conservado únicamente los frescos que iluminan el ábside de esta ermita soriana hubiéramos pensado que sus autores habían renunciado no sólo a este elemento, sino también a la representación de cualquier decoración arquitectónica, separándose así de los de Maderuelo y Berlanga. En consecuencia, este capitel no debería de servir por sí solo para establecer preferencias hacia lo castellano o lo catalán, sino, en todo caso, para valorar las relaciones entre las dos zonas. Sin embargo, como veremos a continuación, existen otros factores que pueden ayudar a aclarar la cuestión.

Uno de ellos, señalado por los autores anteriormente citados, es el empleo del azul, un color que falta en la paleta meseteña y que está, sin embargo, presente en la de la cercana iglesia de Tubilla del Agua y en la de los frescos catalanes ${ }^{35}$. Pese a que lo sucedi-

35 Cf.: M. FONT-ALTABA et al., "Pintura mural", en I. RODA (coord. ${ }^{a}$ ) Ciencias, metodologías y técnicas do en algún caso anterior nos invite a ser cautelosos ante las conclusiones extraídas de este tipo de estudios científicos ${ }^{36}$, los análisis llevados a cabo con motivo de su restauración pueden servirnos de ayuda, entre otras cosas porque son lo único con lo que contamos para poder avanzar en el estudio de estas obras. Dos son, a este respecto, las "extrañezas" recogidas en la memoria técnica: la presencia de aerenita entre los pigmentos y la detección de basalto en los áridos del mortero. En cuanto a la aerenita, de la que se obtiene el color azul, es un mineral que requiere de condiciones muy particulares para su formación. Éstas hacen que su localización peninsular sea muy limitada, focalizándose en zonas próximas al Pirineo aragonés y catalán ${ }^{37}, \mathrm{y}$, fuera de España, pero dentro de la geografía del románico, en algunas regiones del suroeste francés. En otras palabras, se trata de un pigmento difícilmente obtenible

aplicadas a la arqueología, Ed. Fundación "La Caixa", Barcelona, 1992, pp. 227-239.

\footnotetext{
${ }^{36}$ Nos referimos al caso paradigmático de San Bau-
} delio, ya que sus colores han sido también sometidos a modernos análisis espectroscópicos. Entre los resultados obtenidos gracias la analítica espectroscópica figuran los nombres de los minerales (malaquita, litargirio, etc.) que habrían servido para producir los pigmentos de las pinturas. Estos minerales serían propios de la zona (Cf.: H. G. M. EDWARDS, et al., "Medieval Pigments in the Monastery of San Baudelio, Spain: A Raman Spectroscopic Analysis", en Applied Spectroscopy (Society for Applied Spectroscopy), 2001, vol. 55, n. ํ 1, pp. 71-76). Sin embargo, otros científicos han cuestionado muy seriamente los procedimientos empleados para llegar a dichos resultados, por lo que nos invitan a que desde el mundo del Arte adoptemos una actitud más precavida respecto de las conclusiones obtenidas mediante esta clase de investigaciones: "Our intention is to caution researchers at the Arts-Science interface that their findings -in particular those expressed in abstracts and conclusions- will be accepted unquestionably by those unprepared to assess the scientific rigor of the experiments" (Cf.: G. DALE SMITH y R. J. H. CLARK, "Note on Lead (II) Oxide in Mediaeval Frescoes from the Monastery of San Baudelio, Spain", en Applied Spectroscopy, vol. 56, n. ${ }^{\circ}$, 2002, pp. 804-806).

37 También se localiza en Antequera (Málaga), es decir, muy lejos de las coordenadas geográficas de la pintura románica. 
lejos de estos emplazamientos. La segunda "extrañeza" aparece con los áridos fluviales de origen basáltico encontrados en el mortero; aridos que remiten igualmente a esas mismas zonas. De los dos factores, este último es el que resulta más difícil de explicar, pues si bien es compresible que los pintores llevaran consigo pigmentos adquiridos lejos de sus destinos (entre otras cosas por su intrínseca necesidad y por su poco peso), resulta más complicado imaginar que transportasen, a mayores, los áridos correspondientes. Estamos por consiguiente ante dos elementos que pueden decidir con cierta garantía la estirpe pirenaica del taller, especialmente interesante en lo que se refiere al azul, ya que este pigmento sería empleado en varios conjuntos de esa región, entre ellos en Santa María y San Clemente de Taüll.

Dado que los artistas seguramente viajaban con su propio pigmentario, y puesto que resulta lógico suponer que en él figurasen los difícilmente extraíbles de los entornos próximos a sus encargos, es factible conjeturar que una vez terminada su provisión fueran sustituidos, bien por este motivo, o por razones económicas ${ }^{38}$, por otros de más fácil consecución, como los grises. La desaparición del azul en los conjuntos meseteños no tiene, pues, porque oponerse necesariamente a una hipótesis que defienda

\footnotetext{
${ }^{38}$ Es lógico suponer, por su status socioeconómico, que Elines pudiera haberse permitido (salvo que aceptemos y extendamos a sus frescos la ya comentada tesis de García de Guinea) la utilización de ciertos pigmentos, como los azules. En este sentido, la ausencia de este color en la paleta extremaduriense podría indicar un nivel financiero más pobre. Sin embargo, en el caso de San Baudelio, suele admitirse el patronazgo de cierta nobleza ligada a Alfonso I el Batallador (Fortunio Aznárez, señor de Berlanga). Esta nobleza, se habría encargado no sólo de realizar algunas reformas en su arquitectura interior, sino también de la promoción de las pinturas, a cuya iconografía habría impuesto, supuestamente, un carácter nobiliario o palaciego (Cf.: M. GUARDIA PONS, Op. cit., 2011, passim). Así pues, en el caso concreto de San Baudelio, si se admite esta teoría, sería difícil vincular la falta del azul con una financiación deficiente.
}

la unicidad del taller, ya que entra dentro de lo posible que esto llegara realmente a producirse, entre otras razones por la amplitud de su circuito y por las dificultades de comunicación propias de la época. Por eso nos preguntamos si la desaparición del color azul en Maderuelo y Berlanga puede estar relacionada con la recurrente utilización del negro en las indumentarias de este grupo, ya que sabemos, por las improntas del ábside, que en Santa María de Taüll se utilizó este pigmento como preparación para los ropajes azules ${ }^{39}$. No sería entonces raro que ante la carencia del color principal se hubiese recurrido, para pintarlos, al que le servía de base.

En resumen, tanto las variaciones cualitativas como la desaparición del azul pueden ser explicadas desde la hipótesis de talleres diferentes, pero también desde un punto de vista que defienda la unidad del taller. Las primeras, por su capacidad evolutiva, la segunda, por su lejanía al foco de aprovisionamiento. Debemos tener en cuenta, además, que los frescos de San Martín suelen ser considerados como obras del mismo equipo que trabajó en los muros de la muy cercana iglesia de Tubilla del Agua, donde vuelve a hacer aparición el azul; que los lazos estilísticos e iconográficos de estas pinturas burgalesas con las de la Meseta suelen ser igualmente reconocidos; y que las "extrañezas" detectadas en los análisis las vinculan claramente con las comarcas pirenaicas, con cuyos murales (Santa María de Taüll) se relacionan también formalmente, pero, en nuestra opinión, en menor medida que con los del Duero. Por lo tanto podríamos estar ante obras realizadas por un taller formado en el entorno de los Pirineos, que

\footnotetext{
39 Este mismo procedimiento parece haberse empleado también en la célebre Maiestas Domini de San Clemente de Taüll, ya que se ha detectado una subcapa de color negro bajo las muestras azules de su indumentaria. Este color, el negro, sirve, según Manuel Font-Altaba, para reforzar la coloración demasiado transparente del azul (Cf.: M. FONT-ALTABA et al., Op. cit., p. 233).
} 
habría trabajado en el norte de la Meseta y luego descendido hasta encontrarse con la frontera fluvial del Islam, donde habría alcanzado su plenitud artística ${ }^{40}$.

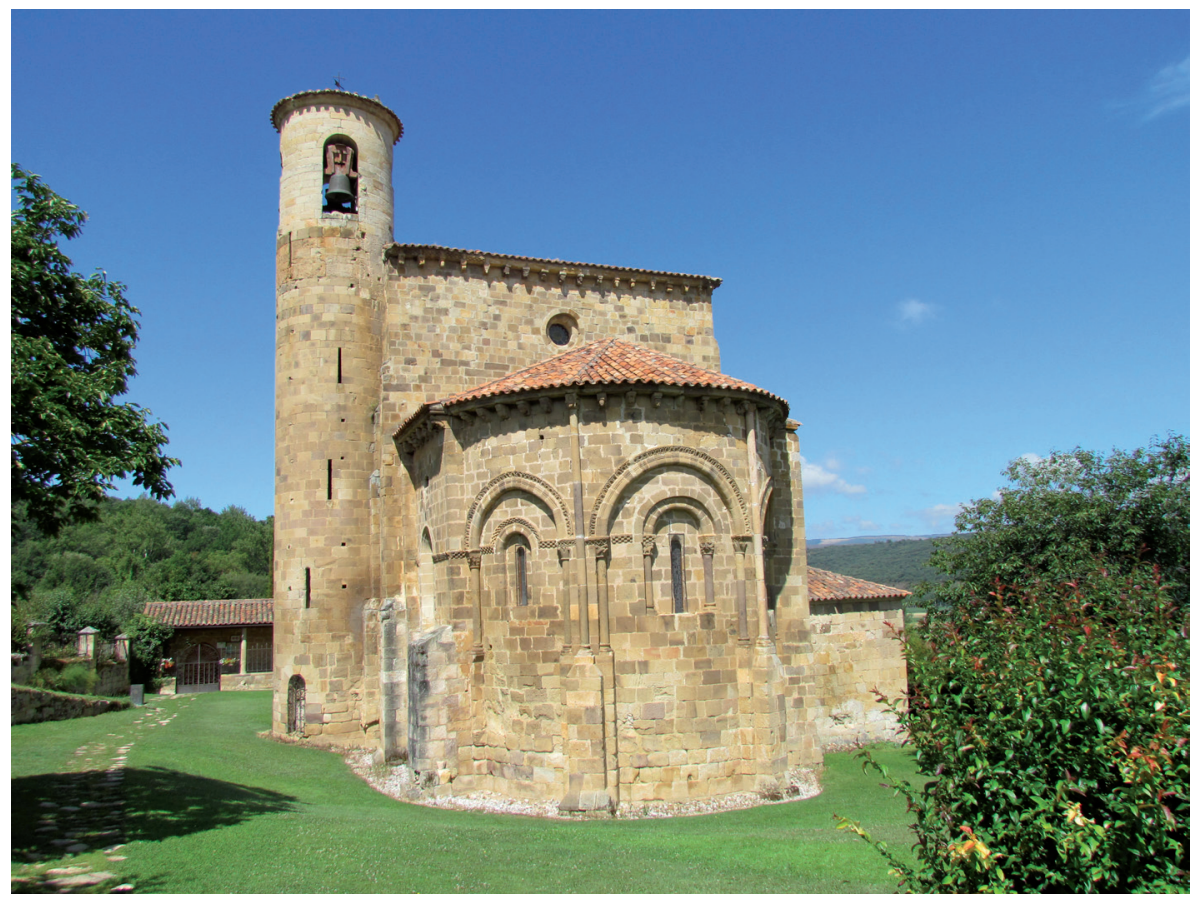

- Fig.1. Exterior de la colegiata

$\overline{40}$ Este es el itinerario comúnmente aceptado. Sin embargo, Joan Sureda contempla la posibilidad del recorrido contrario: "Cabe pensar si el maestro de Santa Maria de Taüll no realizase el proceso inverso, es decir, se trasladara de Castilla a tierras catalanas y aquí, con el mismo o parecido libro de modelos, con un dibujo más pobre y envarado y entusiasmado por el color de la vecina iglesia de Sant Climent, que por lo tanto sería anterior, aunque en pocos años, a Santa Maria, llevase a cabo el ciclo iconográfico de esta última" (Cf.: J. SUREDA PONS, Op. cit., p. 226). 


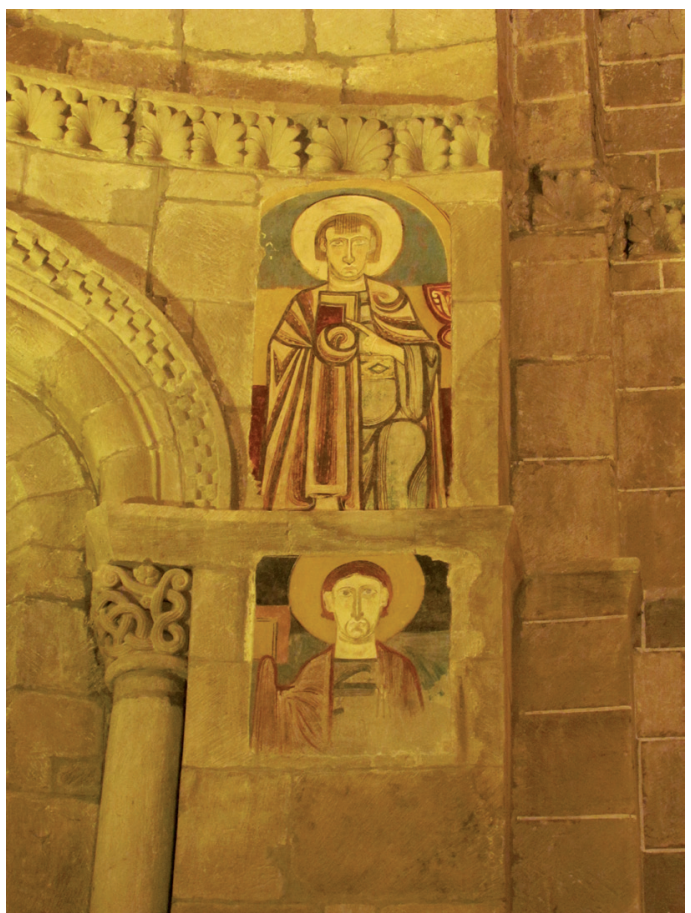

- Fig.2. Los dos apóstoles restaurados

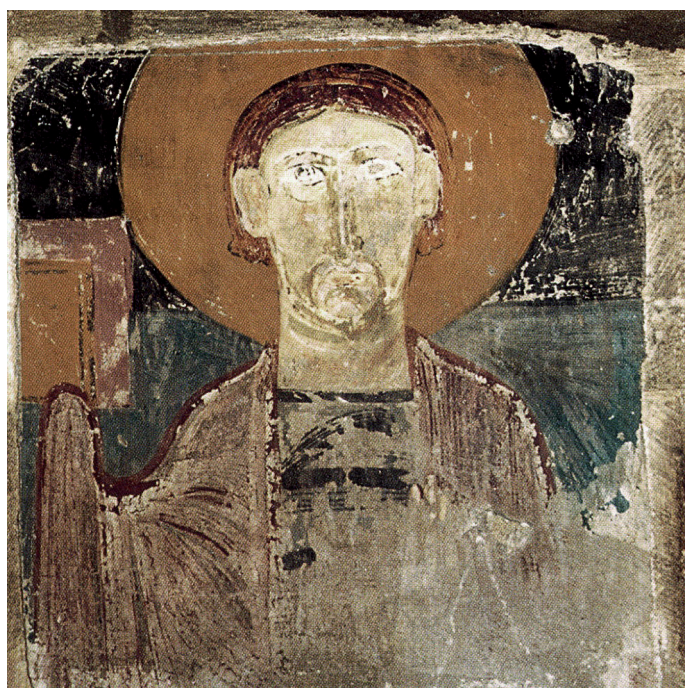

- Fig.4. Apóstol inferior antes de ser restaurado

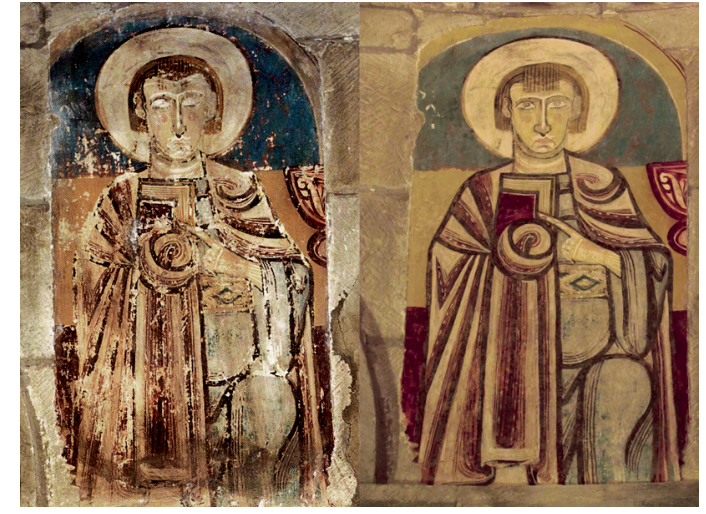

- Fig.3. Apóstol superior antes y después de su restauración

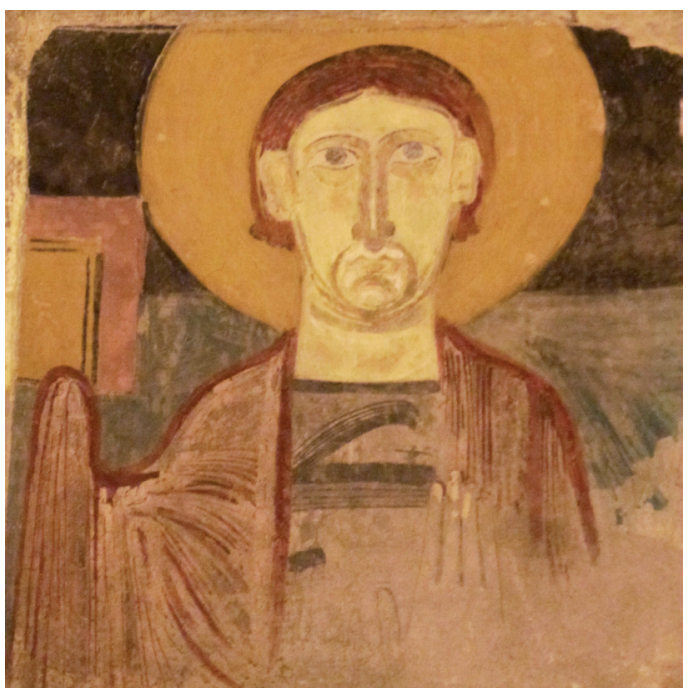

- Fig.5. Apóstol inferior restaurado 


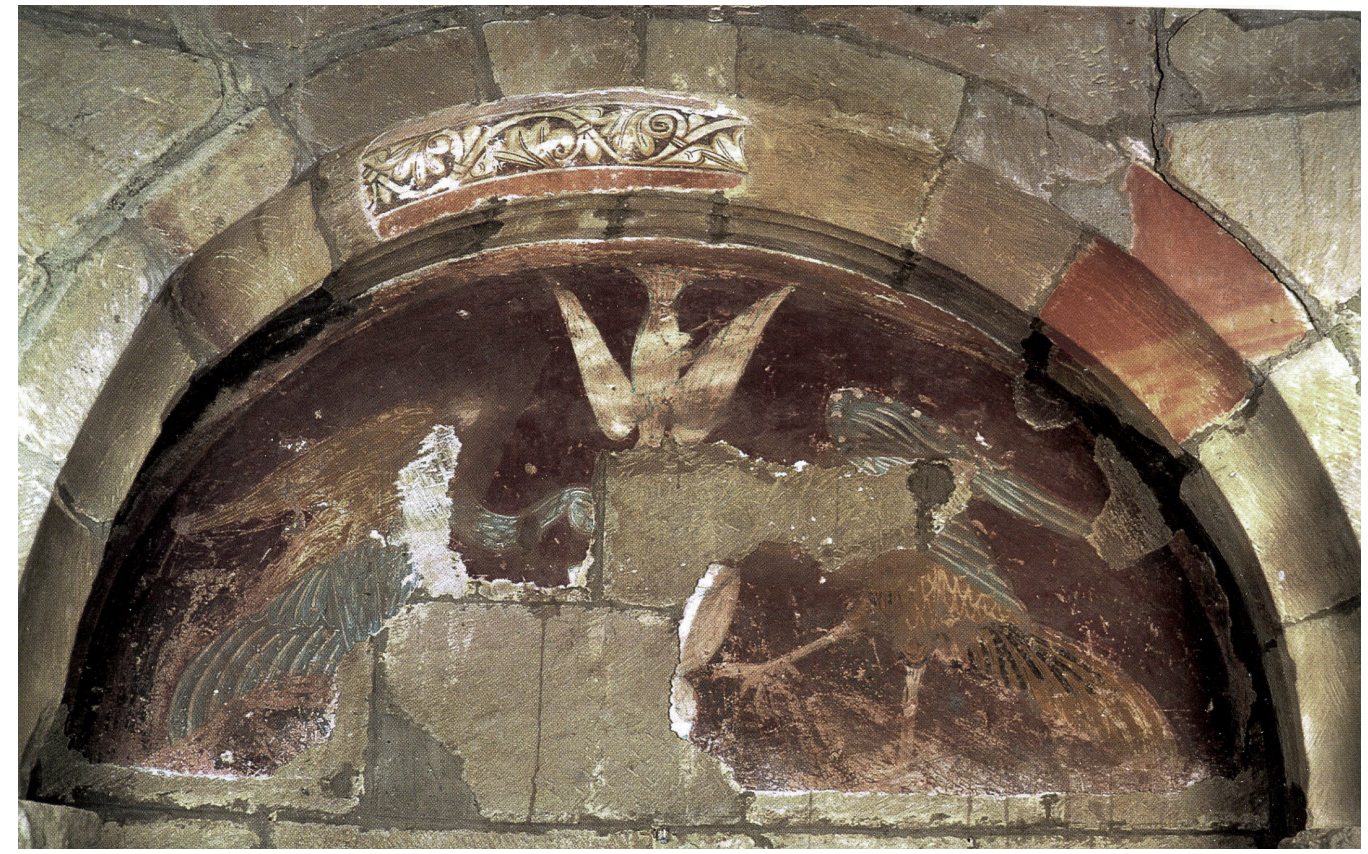

- Fig.6. Arco primero antes de su restauración

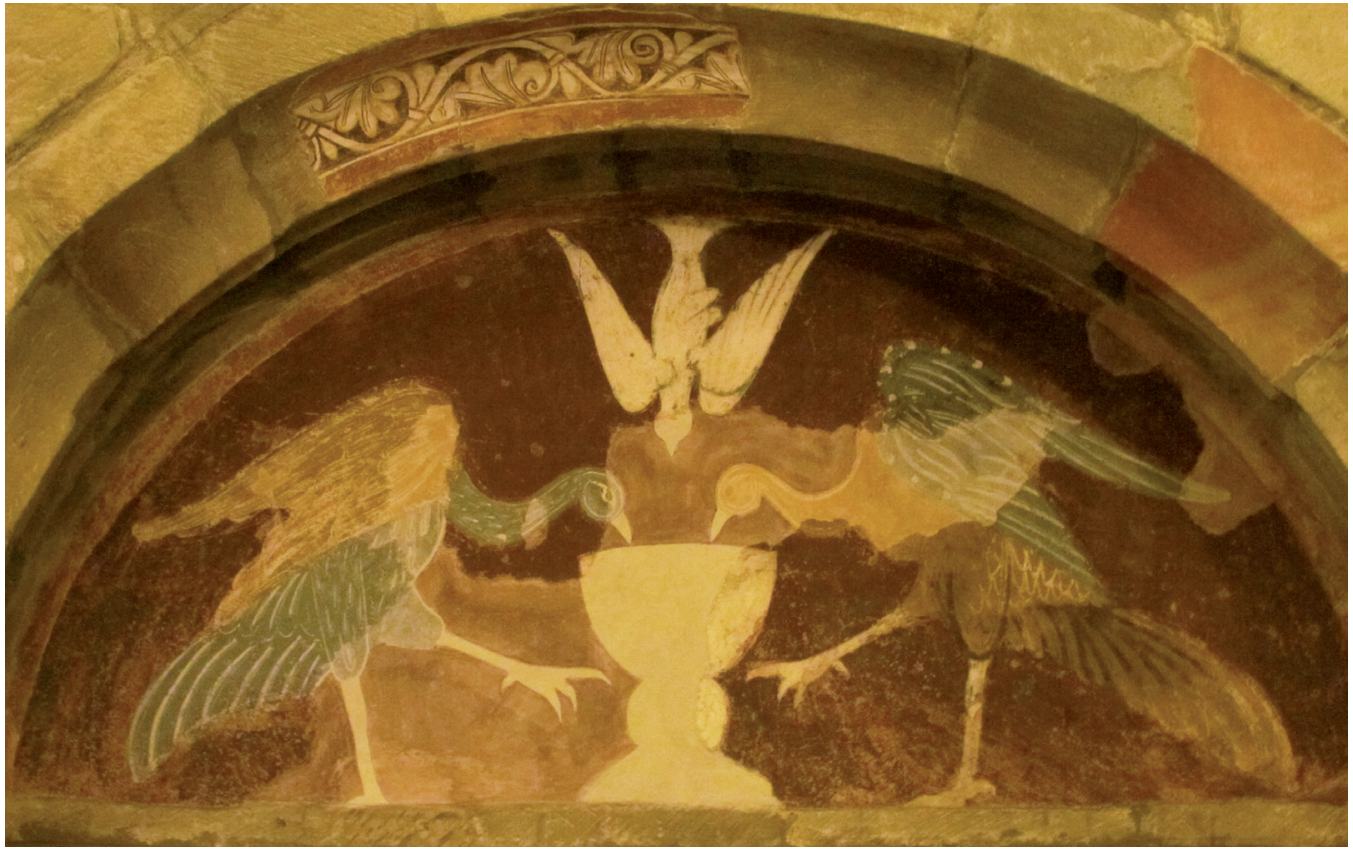

- Fig.7. Arco primero después de su restauración 


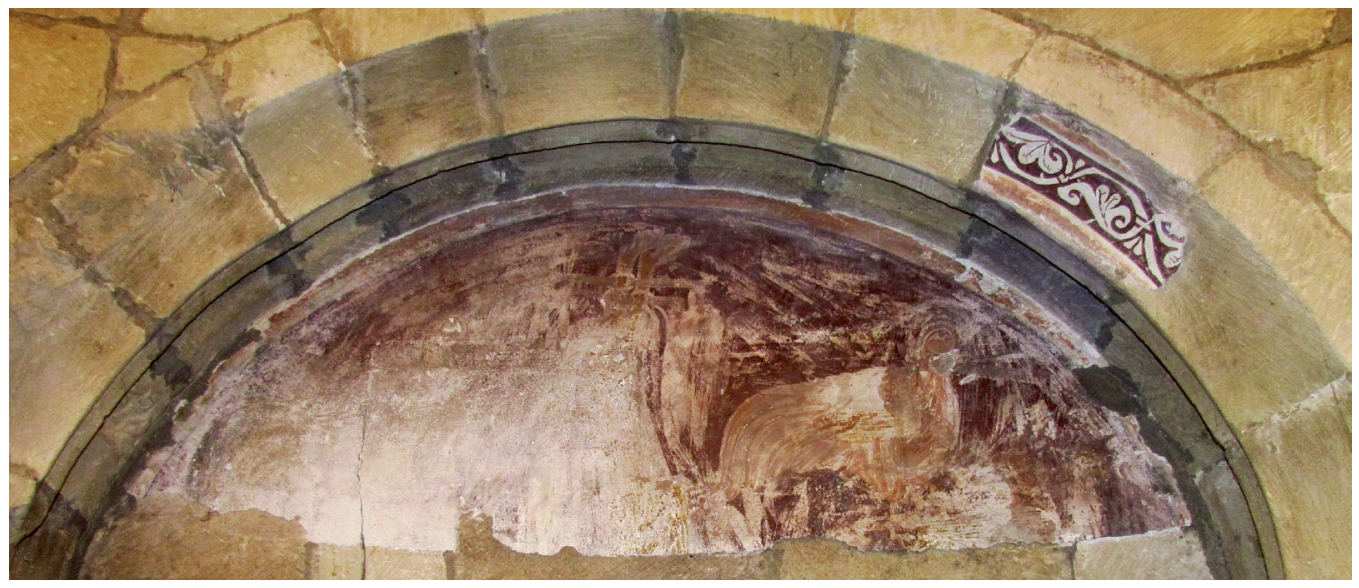

- Fig.8. Arco segundo antes de su restauración

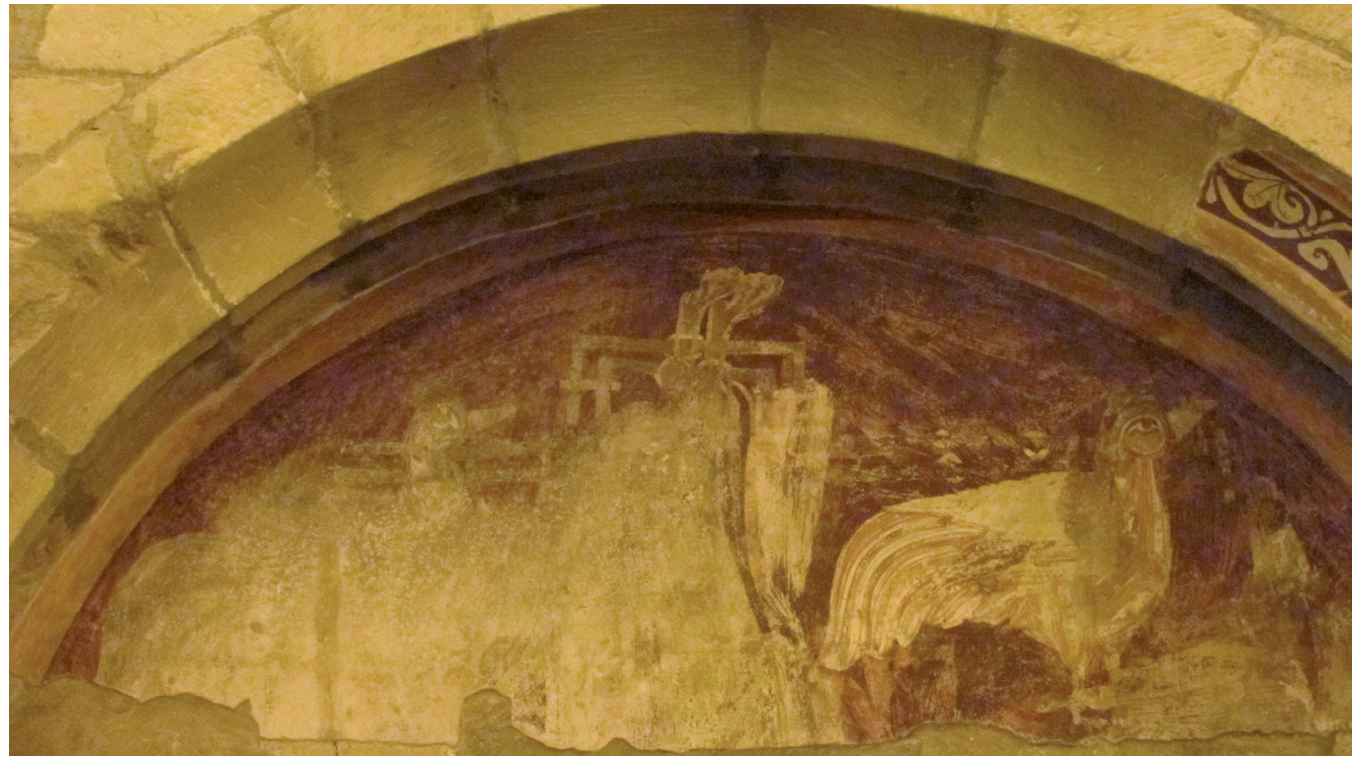

- Fig.9. Arco segundo después de su restauración 


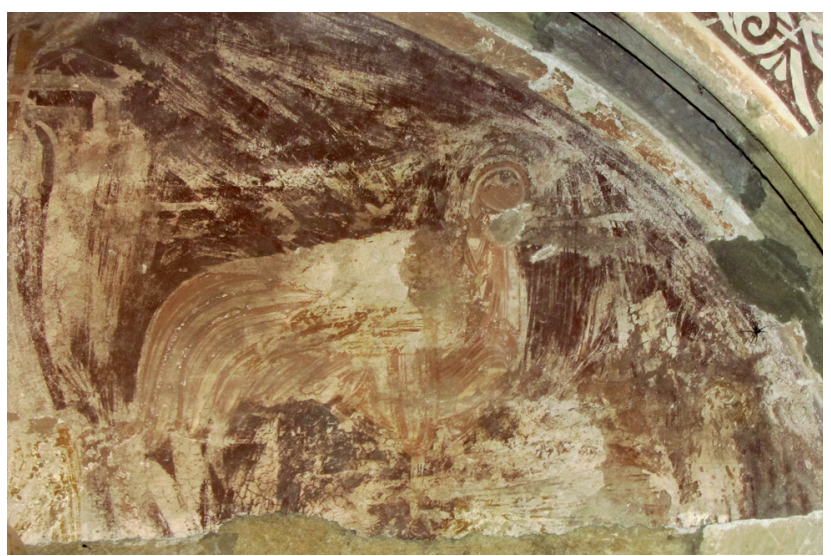

- Fig.10. Arco segundo: detalle de una de las aves

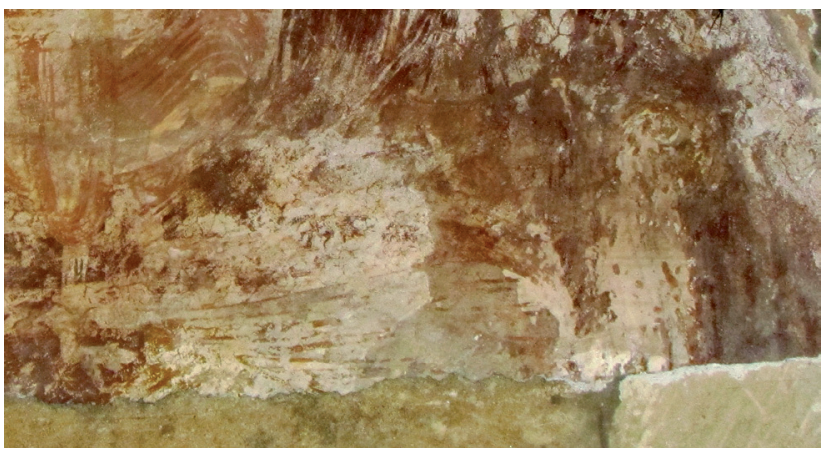

- Fig.11. Arco segundo: detalle del ave situada en la esquina inferior derecha

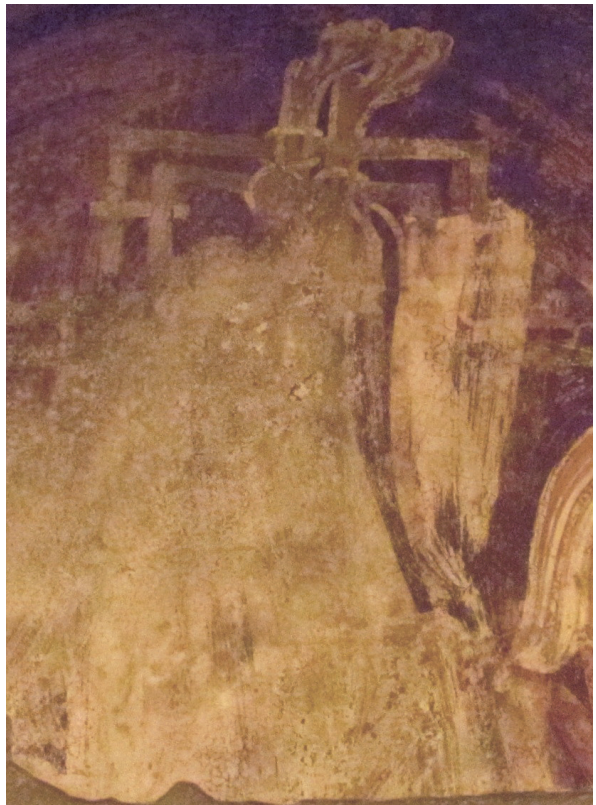

- Fig.12. Arco segundo: detalle del motivo central restaurado 